\title{
Potential repurposing of oncology drugs for the treatment of Alzheimer's disease
}

\author{
Wataru Araki
}

\begin{abstract}
Alzheimer's disease (AD) is the most common form of neurodegenerative dementia, affecting about 30 million people worldwide. Despite recent advances in understanding its molecular pathology, no mechanism-based drugs are currently available that can halt the progression of AD. Because amyloid- $\beta$ peptide $(A \beta)$, a primary component of senile plaques, is thought to be a central pathogenic culprit, several disease-modifying therapies are being developed, including inhibitors of $A \beta$-producing proteases and immunotherapies with anti-A $\beta$ antibodies. Drug repositioning or repurposing is regarded as a complementary and reasonable approach to identify new drug candidates for AD. This commentary will discuss the clinical relevance of an attractive candidate compound reported in a recent paper by Hayes et al. (BMC Medicine 2013) as well as perspectives regarding the possible repositioning of oncology drugs for the treatment of $A D$. See related research article here http://www. biomedcentral.com/1741-7015/11/81

Keywords: Alzheimer's disease, amyloid $\beta$-peptide, disease-modifying drugs, drug repositioning
\end{abstract}

\section{Introduction}

Alzheimer's disease (AD) is a major type of dementia that afflicts about 30 million people worldwide [1]. Pathologically, this disease is characterized by the presence of senile plaques, composed primarily of amyloid $\beta$-peptide $(A \beta)$, and neurofibrillary tangles, composed mainly of phosphorylated tau protein, as well as loss of synapses and neurons [2]. The few drugs currently approved for clinical use, such as donepezil, provide only symptomatic and short-

\footnotetext{
Correspondence: araki@ncnp.go.jp Department of Demyelinating Disease and Aging, National Institute of Neuroscience, National Center of Neurology and Psychiatry, Kodaira, Tokyo 187-8502, Japan
}

(c) 2013 Araki; licensee BioMed Central Ltd. This is an Open Access article distributed under the terms of the Creative Commons Attribution License (http://creativecommons.org/licenses/by/2.0), which permits unrestricted use, distribution, and reproduction in any medium, provided the original work is properly cited. term benefits [3]. Because the accumulation of $A \beta$, particularly the oligomeric species, appears to play a primary pathogenic role in $\mathrm{AD}[4,5]$, it is a primary target for disease-modifying therapeutics of $\mathrm{AD}$. $\mathrm{A} \beta$ is generated by serial cleavages of its precursor, amyloid precursor protein (APP), by $\beta$-secretase (or BACE1) and $\gamma$-secretase [6]. Thus, inhibitors or modulators of these proteases are being developed. Other possible interventions include $A \beta$ immunotherapy to promote $A \beta$ clearance and inhibition of $A \beta$ oligomerization [3,7]. No such drugs have yet been proven clinically effective, despite the urgent need to find new treatments for AD. It, therefore, seems an attractive strategy to assess the anti-A $\beta$ effects of drugs approved for the treatment of other diseases. Such a "drug repositioning" or "repurposing" approach is thought to have several advantages, including reduced time and costs necessary for clinical trials $[8,9]$. A paper by Hayes et al. published recently in BMC Medicine [10] describes an interesting oncology drug that may potentially be used as a diseasemodifying drug in patients with AD.

\section{A new candidate drug for the treatment of AD}

There have been several observations from multiple studies that suggest an inverse relationship between cancer and $\mathrm{AD}$; cancer patients have been shown to have a lower risk of developing $\mathrm{AD}$, and similarly, those diagnosed with $\mathrm{AD}$ seem to have a lower risk of developing cancer $[11,12]$. Therefore, it seemed plausible that anticancer drugs may exert favorable effects on AD. By screening approximately 90 FDA-approved oncology drugs, a group led by Madepalli Lakshmana found that BCNU (1,3 bis(2-chloroethyl)1-nitrosourea or carmustine), an alkylating agent currently used to treat patients with brain tumors, such as malignant gliomas, has potent activity in reducing $\mathrm{A} \beta$ production by cultured cells overexpressing APP [10]. Subsequent analysis of the mechanisms by which $\mathrm{BCNU}$ reduces $\mathrm{A} \beta$ production found that $\mathrm{BCNU}$ increases the secretion of $\mathrm{APP} \alpha$, a protein resulting from alternative $\alpha$-cleavage of APP within the $A \beta$ region, decreases the levels of $C$-terminal fragments of APP and increases the expression of immature APP on 
the cell surface. BCNU did not directly affect the enzymatic activities of $\beta-, \gamma$ - and $\alpha$-secretases. Accordingly, BCNU appears to reduce $\mathrm{A} \beta$ by altering the trafficking and processing of APP without directly affecting secretase activities. In addition, BCNU was found to increase transforming growth factor (TGF)- $\beta 1$ levels in cell media and cell extracts, an intriguing observation in view of the involvement of the TGF- $\beta 1$ pathway in $\mathrm{AD}$ [13].

Following these cell-based experiments, the authors performed in vivo experiments to determine whether BCNU could reduce $A \beta$ production in a transgenic mouse model, in which $A \beta$ plaques appear as early as six months of age. Intraperitoneal injection of $0.5 \mathrm{mg} / \mathrm{kg} \mathrm{BCNU}$, a non-toxic dose, for 60 days, from four to six months of age, resulted in the marked reduction of $A \beta$ plaque burden in the brain. Furthermore, BCNU treatment decreased levels of $\mathrm{A} \beta$ and APP C-terminal fragments and increased levels of secreted $\mathrm{APP} \alpha$ in mouse brains, recapitulating the changes observed in cell cultures. Moreover, BCNU treatment reduced the number of Iba1-positive microglia, indicating that this agent suppresses microglial activation in the mouse brain. This effect may be related to the TGF- $\beta 1$ pathway, since TGF- $\beta 1$ plays a constitutive role in the suppression of inflammation [14]. A modest increase in astroglial TGF- $\beta 1$ production in APP transgenic mice has been shown to result in a significant reduction of $A \beta$ [15]. Moreover, a specific impairment of the TGF- $\beta 1$ signaling pathway has been demonstrated in the AD brain, and TGF- $\beta 1$ has been found to exert neuroprotective effects against various insults, including $A \beta$ toxicity $[13,14]$. Thus, $\mathrm{BCNU}$ treatment may reduce $\mathrm{A} \beta$ production through combined effects on APP trafficking and processing and on the TGF- $\beta 1$ pathway.

\section{Oncology drugs have potential utility for AD}

The study by Hayes et al. identified BCNU as a potential anti-A $\beta$ drug [10]. However, several questions need to be investigated, including whether chronic treatment with $\mathrm{BCNU}$ can prevent cognitive impairment in the mouse model and whether BCNU up-regulates TGF- $\beta 1$ in vivo. Because $\mathrm{BCNU}$ is metabolized very rapidly in the brain, the authors suggested that its anti-amyloidogenic effects may result from the action of one of its metabolites [10]; however, such a compound remains to be identified. Safety is a major issue to be considered. For the treatment of brain tumors, patients are implanted with $\mathrm{BCNU}$ wafers to avoid systemic side effects. Although BCNU exhibited a robust $\mathrm{A} \beta$-reducing effect in vivo at non-toxic concentrations, the safety of long-term use has not yet been established. If a metabolite of BCNU with a potent anti-A $\beta$ action is identified, a safer compound with less toxicity may be developed.

Potential AD therapy with existing oncology drugs appears to be a promising strategy. For instance, treatment with bexarotene, an agonist of retinoid X receptors (RXRs) that is used to treat patients with $\mathrm{T}$ cell lymphoma, was recently found to lead to pathological and behavioral improvements in transgenic mouse models of AD [16]. Bexarotene stimulates the expression of apolipoprotein $\mathrm{E}$ (ApoE) and its lipid transporters ABCA1 and ABCG1, and facilitates $A \beta$ clearance in an ApoE dependent manner. This agent also appears to promote microglial phagocytosis. Thus, RXR agonists may be of therapeutic utility in the treatment of AD. In addition, drugs that activate retinoic acid receptors (RARs), such as acitretin and tamibarotene, which are used to treat psoriasis and acute promyelocytic leukemia, respectively, have been reported to have beneficial effects on APP processing by enhancing non-amyloidogenic $\alpha$-secretase processing of APP, probably through the induction of $\alpha$-secretase (or ADAM10) expression $[17,18]$. Because the administration of RAR agonists to APP transgenic mice decreases $A \beta$ levels in the brain $[17,18]$, they are promising candidate drugs for the treatment of AD. Phase II clinical trials are underway to validate their clinical efficacy. Other oncology drugs with potential utility for AD include imatinib and paclitaxel, but both have the drawbacks of poor central nervous system penetration [9].

\section{Conclusions}

$\mathrm{BCNU}$ is a unique new addition to the list of candidate oncology drugs with potential clinical efficacy in AD. More preclinical work, including clarification of its mechanisms of action, is essential before BCNU proceeds to clinical trials. Needless to say, various classes of drugs other than those used for chemotherapy are regarded as potential candidate drugs for $\mathrm{AD}[8,9]$. Future rigorous efforts to develop disease-modifying drugs through drug repositioning or repurposing may lead to the emergence of successful therapies for AD.

\section{Abbreviations \\ Aß: amyloid $\beta$-peptide; AD: Alzheimer's disease; ApoE: apolipoprotein E; APP: amyloid precursor protein; BCNU: 1,3 bis(2-chloroethyl)-1-nitrosourea or carmustine; RARs: retinoic acid receptors; RXRs: retinoid X receptors; TGF: transforming growth factor}

Authors' information

WA is a neurologist and is a section chief at the Department of Demyelinating Disease and Aging, National Institute of Neuroscience, National Center of Neurology and Psychiatry (Japan).

\section{Competing interests}

The author declares that they have no competing interests.

Received: 12 February 2013 Accepted: 26 March 2013

Published: 26 March 2013

\section{References}

1. Brookmeyer R, Johnson E, Ziegler-Graham K, Arrighi HM: Forecasting the global burden of Alzheimer's disease. Alzheimers Dement 2011, 7:61-73 
2. LaFerla FM, Oddo S: Alzheimer's disease: abeta, tau and synaptic dysfunction. Trends Mol Med 2005, 11:170-176.

3. Klafki HW, Staufenbiel M, Kornhuber J, Wiltfang J: Therapeutic approaches to Alzheimer's disease. Brain 2006, 129:2840-2855.

4. Hardy J, Selkoe DJ: The amyloid hypothesis of Alzheimer's disease: progress and problems on the road to therapeutics. Science 2002, 297:353-356.

5. Walsh DM, Selkoe DJ: A beta oligomers - a decade of discovery. J Neurochem 2007, 101:1172-1184.

6. De Strooper B, Vassar R, Golde T: The secretases: enzymes with therapeutic potential in Alzheimer disease. Nat Rev Neurol 2010, 6:99-107.

7. Salomone S, Caraci F, Leggio GM, Fedotova J, Drago F: New pharmacological strategies for treatment of Alzheimer's disease: focus on disease modifying drugs. Br J Clin Pharmacol 2012, 73:504-517.

8. Corbett A, Pickett J, Burns A, Corcoran J, Dunnett SB, Edison P, Hagan JJ, Holmes C, Jones E, Katona C, Kearns I, Kehoe P, Mudher A, Passmore A, Shepherd N, Walsh F, Ballard C: Drug repositioning for Alzheimer's disease. Nat Rev Drug Discov 2012, 11:833-846.

9. Appleby BS, Nacopoulos D, Milano N, Zhong K, Cummings JL: A review: treatment of Alzheimer's disease discovered in repurposed agents. Dement Geriatr Cogn Disord 2013, 35:1-22.

10. Hayes CD, Dey D, Palavicini JP, Wang H, Patkar KA, Minond D, Nefzi A, Lakshmana MK: Striking reduction of amyloid plaque burden in an Alzheimer's mouse model after chronic administration of carmustine. BMC Med .

11. Roe CM, Behrens MI, Xiong C, Miller JP, Morris JC: Alzheimer disease and cancer. Neurology 2005, 64:895-898.

12. Driver JA, Beiser A, Au R, Kreger BE, Splansky GL, Kurth T, Kiel DP, Lu KP, Seshadri S, Wolf PA: Inverse association between cancer and Alzheimer's disease: results from the Framingham Heart Study. BMJ 2012, 344:e1442.

13. Caraci F, Battaglia G, Bruno V, Bosco P, Carbonaro V, Giuffrida ML, Drago F, Sortino MA, Nicoletti F, Copani A: TGF- $\beta 1$ pathway as a new target for neuroprotection in Alzheimer's disease. CNS Neurosci Ther 2011, 17:237-249.

14. Rubio-Perez JM, Morillas-Ruiz JM: A review: inflammatory process in Alzheimer's disease, role of cytokines. ScientificWorldJournal 2012, 2012:756357.

15. Wyss-Coray T, Lin C, Yan F, Yu GQ, Rohde M, McConlogue L, Masliah E, Mucke L: TGF- $\beta 1$ promotes microglial amyloid- $\beta$ clearance and reduces plaque burden in transgenic mice. Nat Med 2001, 7:614-618.

16. Cramer PE, Cirrito JR, Wesson DW, Lee CY, Karlo JC, Zinn AE, Casali BT, Restivo JL, Goebel WD, James MJ, Brunden KR, Wilson DA, Landreth GE: ApoE-directed therapeutics rapidly clear $\beta$-amyloid and reverse deficits in AD mouse models. Science 2012, 335:1503-1506.

17. Tippmann F, Hundt J, Schneider A, Endres K, Fahrenholz F: Up-regulation of the alpha-secretase ADAM10 by retinoic acid receptors and acitretin. FASEB J 2009, 23:1643-1654.

18. Kawahara K, Nishi K, Suenobu M, Ohtsuka H, Maeda A, Nagatomo K, Kuniyasu A, Staufenbiel M, Nakagomi M, Shudo K, Nakayama H: Oral administration of synthetic retinoid Am80 (Tamibarotene) decreases brain beta-amyloid peptides in APP23 mice. Biol Pharm Bull 2009, 32:1307-1309.

Pre-publication history

The pre-publication history for this paper can be accessed here: http://www.biomedcentral.com/1741-7015/11/82/prepub

doi:10.1186/1741-7015-11-82

Cite this article as: Araki: Potential repurposing of oncology drugs for the treatment of Alzheimer's disease. BMC Medicine 2013 11:82.

\section{Submit your next manuscript to BioMed Central and take full advantage of:}

- Convenient online submission

- Thorough peer review

- No space constraints or color figure charges

- Immediate publication on acceptance

- Inclusion in PubMed, CAS, Scopus and Google Scholar

- Research which is freely available for redistribution

Submit your manuscript at www.biomedcentral.com/submit
Biomed Central 